\title{
Efeito de temperaturas na expansão, número de lesões e severidade da mancha- amarela da folha do trigo
}

\author{
Camila Ranzi ${ }^{1,2}$; Carlos Alberto Forcelini ${ }^{1}$; Carolina Cardoso Deuner ${ }^{1}$
}

${ }^{1}$ Universidade de Passo Fundo, Campus I, Bairro São José - BR 285 - KM 171, Caixa Postal 611, Passo Fundo, RS, Brasil. CEP 99052-900.²Parte

da tese de doutorado.

Autor para correspondência: Camila Ranzi (camila_ranzi@hotmail.com)

Data de chegada: 08/05/2015. Aceito para publicação em: 10/09/2015.

$10.1590 / 0100-5405 / 2095$

\section{RESUMO}

Ranzi, C.; Forcelini, C.A.; Deuner, C.C. Efeito de temperaturas na expansão, número de lesões e severidade da mancha-amarela da folha do trigo. Summa Phytopathologica, v.41, n.4, p.311-314, 2015.

A mancha-amarela da folha do trigo, causada pelo fungo Pyrenophora triticirepentis, forma anamórfica Drechslera tritici-repentis, é uma das principais doenças da cultura. A expansão da lesão é um importante componente dessa epidemia, e assim como os demais, podem ser influenciados pela temperatura. Por isso, objetivou-se a realização do trabalho para avaliar o efeito da temperatura na expansão e no número de lesões, bem como na severidade da manchaamarela do trigo. O trabalho foi conduzido em câmaras climatizadas, sob cinco temperaturas $\left(10,15,20,25\right.$ e $\left.30^{\circ} \mathrm{C}\right)$, com as cultivares de trigo Mirante e Fundacep Horizonte. As plantas foram inoculadas no estádio de três folhas expandidas, com $3 \times 10^{3}$ conídios $/ \mathrm{mL}$ de suspensão em água. As lesões foram medidas a cada três dias a partir do aparecimento dos sintomas. Contou-se as lesões por folha e deram-se notas de severidade estimada. O delineamento utilizado foi de blocos casualizados com quatro repetições, sendo cada vaso uma repetição. A temperatura influenciou positivamente o aumento da doença, sendo que, a $30^{\circ} \mathrm{C}$ o número e crescimento das lesões, bem como, a severidade da doença foram maiores.

Palavras-chave: componentes da epidemia, Drechslera tritici-repentis, Triticum aestivum

\section{ABSTRACT}

Ranzi, C.; Forcelini, C.A.; Deuner, C.C. Effect of temperature on the expansion, number of lesions and severity of tan spot of wheat. Summa Phytopathologica, v.41, n.4, p.311-314, 2015.

Tan spot of wheat, caused by the fungus Pyrenophora tritici-repentis, anamorphic form Drechslera tritici-repentis, is one of the major diseases affecting this crop. The lesion expansion is an important component of this epidemic and, similarly to others, can be influenced by temperature. Therefore, the aim of this study was to evaluate the effect of temperature on the expansion and number of lesions, as well as on the severity of tan spot of wheat. The study was conducted in climatic chambers at five temperatures $\left(10,15,20,25\right.$ and $\left.30^{\circ} \mathrm{C}\right)$ with the cultivars Mirante and Fundacep Horizonte. Plants were inoculated, in the stage of three expanded leaves, with $3 \times 10^{3}$ conidia/ml suspension in water. The lesions were measured at every three days from the onset of symptoms. In addition, lesions were counted per leaf and severity scores were estimated. The adopted design was in randomized block with four replicates, and each pot constituted a replicate. Temperature positively influenced the disease increase, and at $30^{\circ} \mathrm{C}$ the number and progress of lesions, as well as the severity of the disease, were greater.

Additional key-words: epidemic components, Drechslera tritici-repentis, Triticum aestivum

A mancha-amarela da folha do trigo é uma doença foliar que tem potencial para causar severos danos, reduzindo a área de fotossíntese das folhas, resultando em redução de enchimento de grãos e do número de grãos (12).

A dispersão e infecção por $P$. tritici-repentis pode desenvolver-se entre as temperaturas de 10 a $30^{\circ} \mathrm{C}$ e com umidade entre 6 a $48 \mathrm{~h} .(6 ; 4$; 10). Já Santana (11), afirma que as condições ótimas para ocorrência da doença são temperatura entre 18 e $28^{\circ} \mathrm{C}$ e molhamento folhar de 30 horas. Segundo Amorim (1), o ambiente regula o desenvolvimento das epidemias, podendo, inclusive, impedir sua ocorrência mesmo que hospedeiros suscetíveis e patógenos virulentos estejam presentes. A temperatura age como catalisador dos processos biológicos, razão pela qual tanto as plantas como os patógenos requerem uma temperatura mínima para crescer e desenvolver normalmente suas atividades (8).
Reis et al.(9), enfatiza também que a produção de conídios ocorre de $-22,0$ a $-26,0 \mathrm{Mpa}$, ou seja ficando entre 83 a $85 \%$ de umidade relativa do ar e que a luz é necessária a formação de conidióforos, no entanto, os conídios são produzidos somente no escuro e sob temperatura de 10 a $25^{\circ} \mathrm{C}$, com um ótimo de $21^{\circ} \mathrm{C}$.

A maioria dos estudos relacionando ambiente à ocorrência da mancha-amarela é direcionada às condições necessárias à infecção da planta pelo patógeno. Contudo, por ser este um fungo necrotrófico com ativa produção de toxinas, as lesões crescem significativamente no período subseqüente à infecção, processo conhecido como expansão de lesão. A influência da temperatura sobre o crescimento da área necrosada ainda é pouco conhecida, por isso o trabalho foi desenvolvido com o objetivo de avaliar o efeito da temperatura sobre a expansão, número de lesões e severidade da mancha-amarela do trigo. 


\section{MATERIAL E MÉTODOS}

Os experimentos foram conduzidos no Laboratório de Fitopatologia e câmaras climatizadas da Faculdade de Agronomia e Medicina Veterinária da Universidade de Passo Fundo. As plantas foram cultivadas em copos plásticos de $500 \mathrm{~mL}$, com solo. Utilizaram-se as cultivares: Mirante e Fundacep Horizonte. Mantiveram-se em média cinco plantas por vaso. O delineamento utilizado foi de blocos casualizados com quatro repetições, sendo cada vaso uma repetição. As plantas foram mantidas em câmaras climatizadas com temperatura de $18{ }^{\circ} \mathrm{C}$ até ser realizada a inoculação do fungo, quando então foram separadas em grupos, como descrito posteriormente.

Isolou-se o patógeno a partir de folhas de trigo da cultivar BRS Guamirim, procedentes do município de Coxilha-RS. Lesões típicas de mancha-amarela foram cortadas em fragmentos de $5 \mathrm{~mm}^{2}$ e desinfestadas em solução aquosa de hipoclorito de sódio (1\%) por três minutos, sendo então lavadas três vezes com água destilada para retirar o excesso do desinfetante. Os fragmentos foram distribuídos em caixas de acrílico, tipo gerbox, contendo uma espuma de náilon e duas folhas sobrepostas de papel filtro, umedecidas com água destilada e esterilizada (ADE), formando uma câmara úmida. As caixas foram mantidas em ambiente com temperatura de $25 \pm 2^{\circ} \mathrm{C}$ e fotoperíodo de 12 horas. Após cinco dias, com o auxílio de uma agulha histológica flambada, estruturas do patógeno foram transferidas para placas de Petri contendo meio de cultura batata-sacarose-ágar preparado segundo Fernandez (3). Em seguida, procedeu-se o isolamento monospórico, onde uma alíquota de $10 \mathrm{~mL}$ de água destilada e esterilizada foi adicionada a uma placa contendo colônia pura de D. tritici-repentis. Com auxílio de um pincel a colônia foi friccionada para remoção dos esporos da superfície. A suspensão foi então vertida em um Becker, com posterior coleta de amostras de $10 \mu \mathrm{L}$ para contagem do número de conídios em microscópio óptico com magnitude de 100 vezes. Uma amostra de $0,5 \mathrm{~mL}$ dessa suspensão foi espalhada sobre a superfície de meio de cultura ágar-água e incubada em câmara de crescimento por $8 \mathrm{~h}$, a $25 \pm 2{ }^{\circ} \mathrm{C}$, na presença de luz. Com auxílio de lupa e estilete, pequenas porções de meios contendo um esporo germinado foram transferidas para outras placas contendo meio de cultura BDA, sendo incubadas até o crescimento das colônias puras do fungo.

Para esporulação em laboratório do fungo $D$. tritici-repentis primeiramente, discos de $5 \mathrm{~mm}$ de diâmetro, obtidos de colônias puras do fungo, foram transferidos para placas com meio de cultura V8-ágar e incubados em BOD, a $25^{\circ} \mathrm{C}$ e escuro contínuo por cinco dias. As colônias foram cobertas com água destilada e esterilizada e pressionadas suavemente com a base de um tubo de ensaio. $\mathrm{O}$ excesso de água foi removido e as placas novamente incubadas a $25^{\circ} \mathrm{C}$, porém na presença de luz contínua por 24 horas. A incubação foi então alterada para 15 ${ }^{\circ} \mathrm{C}$ e escuro contínuo por outras 24 horas. Os conídios formados foram removidos com pincel, usando água destilada e espalhante Tween, na proporção de uma gota para $500 \mathrm{~mL}$ de água.

A suspensão de conídios foi ajustada para $3 \times 10^{3}$ conídios $/ \mathrm{mL}$. A inoculação foi realizada com pulverizador manual de $500 \mathrm{~mL}$, até o ponto de escorrimento, em plantas no estádio de três folhas expandidas. As plantas foram cobertas com capas plásticas para manutenção de câmara úmida por 24 horas. As plantas foram levadas para diferentes câmaras com as temperaturas estabelecidas de $10,15,20,25$ e $30^{\circ} \mathrm{C}$. O trabalho foi realizado duas vezes.

A partir do surgimento das lesões, cerca de três dias após a inoculação do fungo, escolheram-se aleatoriamente 48 lesões/ tratamento, a maioria na terceira folha expandida, as quais foram identificadas com marcadores permanentes para avaliações sequenciais do seu tamanho. As lesões foram mensuradas quatro vezes, em intervalos de três dias, com um paquímetro digital, considerando o comprimento e largura da lesão. Como as lesões não são retangulares, utilizou-se um fator de correção para as lesões $(0,66)$ obtido através da comparação da área real da lesão com as medições de largura e comprimento. Os resultados foram submetidos à análise de variância e regressão não linear pelo modelo $y=a e^{b x}$, onde $y=$ área da lesão, $a$ = parâmetro da equação, $x=$ tempo em dias e $b=$ taxa de expansão de lesão. Posteriormente, os cultivares foram comparados pelo teste de Tukey a 5\% de probabilidade.

\section{RESULTADOS E DISCUSSÃO}

A temperatura de incubação exerceu efeito significativo sobre a taxa de progresso, severidade e número de lesões da doença. As médias de expansão de lesão observada em cada cultivar diferiram estatisticamente entre as temperaturas, sendo que a maior taxa de expansão foi observada na temperatura de $30{ }^{\circ} \mathrm{C}\left(0,23 \mathrm{~mm}^{2} / \mathrm{dia}\right)$, seguidas das temperaturas 25 e $20^{\circ} \mathrm{C}$, as quais não diferiram entre si (Figura 1). A menor taxa foi
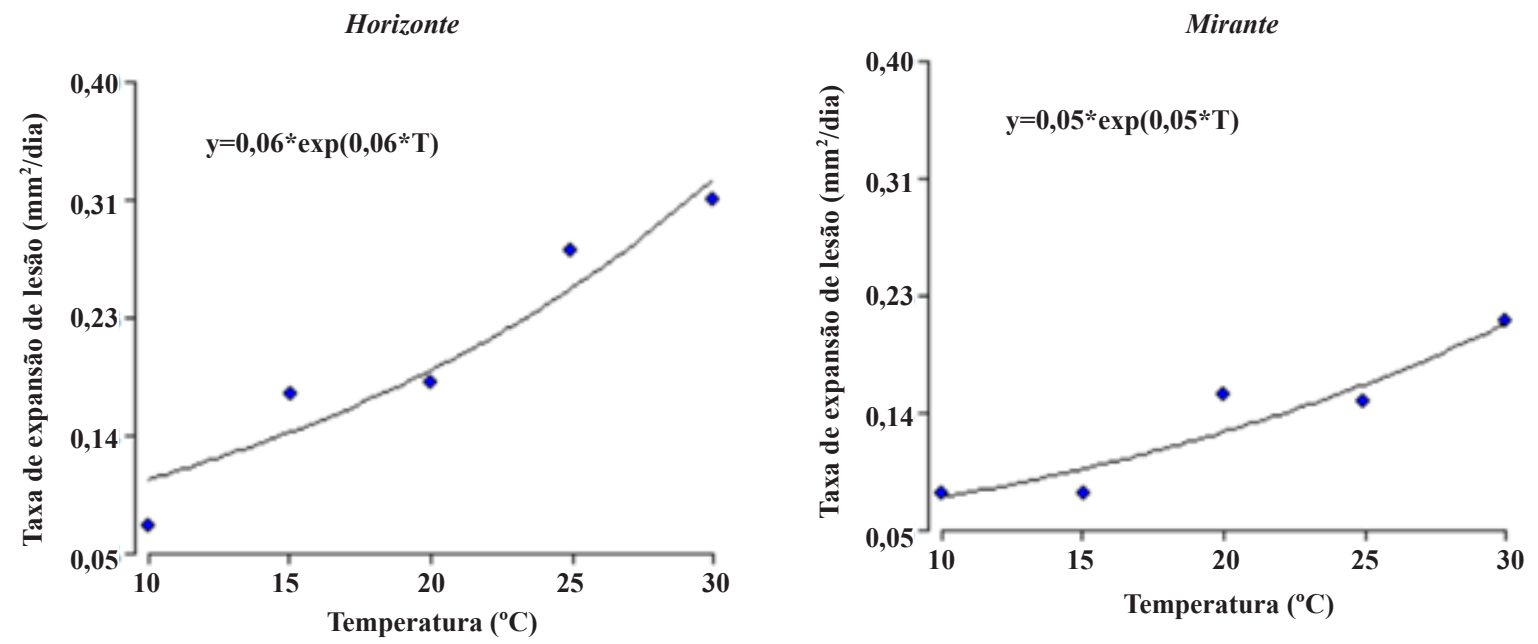

Figura 1. Taxa de expansão de lesão $\left(\mathrm{mm}^{2} /\right.$ dia) da mancha-amarela em função de diferentes temperaturas, em duas cultivares de trigo (Mirante e Fundacep Horizonte), após 12 dias da inoculação. UPF, Passo Fundo, 2012. 
na temperatura de $10{ }^{\circ} \mathrm{C}\left(0,07 \mathrm{~mm}^{2} / \mathrm{dia}\right)$. Houve diferença estatística também entre as cultivares, onde a Fundacep Horizonte se sobressaiu, apresentando um progresso maior $(0,20)$, do que a Mirante $\left(0,13 \mathrm{~mm}^{2} /\right.$ dia).

Em trabalho realizado por Prates \& Fernandes (7), com a mancha-marrom do trigo, causada pelo fungo Bipolaris sorokiniana, a temperatura também exerceu influência na expansão das lesões, sendo que as taxas foram mais elevadas nas temperaturas de 23 a 30 ${ }^{\circ} \mathrm{C}$. Neste trabalho, as maiores taxas foram observadas na faixa de 25 a $30^{\circ} \mathrm{C}$. Em epidemias naturais a taxa de expansão de lesão, em diferentes patosistemas, além da temperatura, pode variar em função de outros fatores como a posição da folha (2), idade da lesão ou do hospedeiro (13) e a densidade de lesões. Neste trabalho, as variáveis acima foram uniformizadas, de modo a não influenciar nos resultados.

A severidade estimada da doença diferiu entre as temperaturas de exposição e as cultivares. A maior severidade média foi alcançada na temperatura de $30^{\circ} \mathrm{C}(51,66 \%)$, diferindo das demais (Figura 2). As menores severidades foram observadas quando as cultivares foram submetidas à temperatura mais baixa $\left(10^{\circ} \mathrm{C}\right)$. Entre as cultivares, constatou-se maior severidade na Fundacep Horizonte (28\%). O valor médio de severidade alcançado para a Mirante foi de 11,47\%.

Em trabalho de Hosford et al (4), modificado por Reis et al (9), foi mostrado uma interação entre temperatura $\mathrm{x}$ molhamento utilizando um cultivar suscetível, onde quanto maior a temperatura $\left(30^{\circ} \mathrm{C}\right)$ e maior molhamento foliar (24h), resultaram na maior severidade da doença, alcançando 53,9\%. Este valor é semelhante ao encontrado neste estudo, onde a temperatura de $30{ }^{\circ} \mathrm{C}$ a cultivar Fundacep Horizonte apresentou severidade de 51,66\%. Segundo Lamari e Bernier (5), a resistência é expressa através de lesões pequenas marrons escuras que não aumentam de tamanho, enquanto a susceptibilidade é expressa por manchas marrons escuras cercadas por extensa necrose e clorose que podem envolver toda a folha.
Horizonte

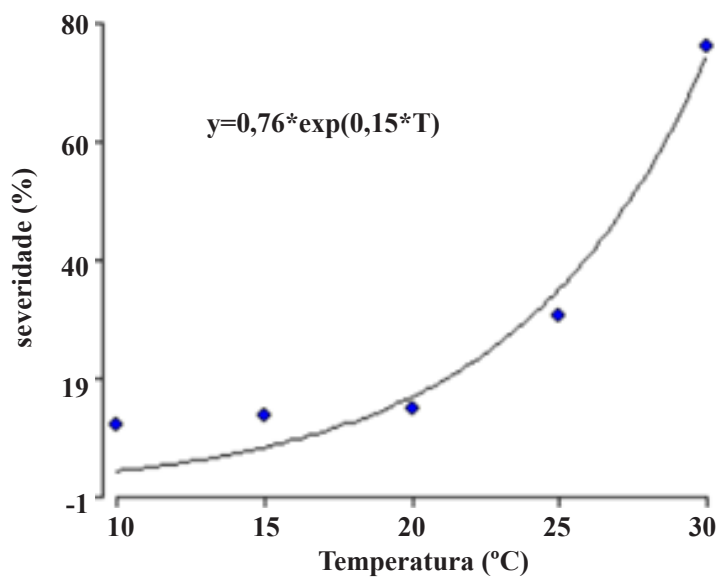

Mirante

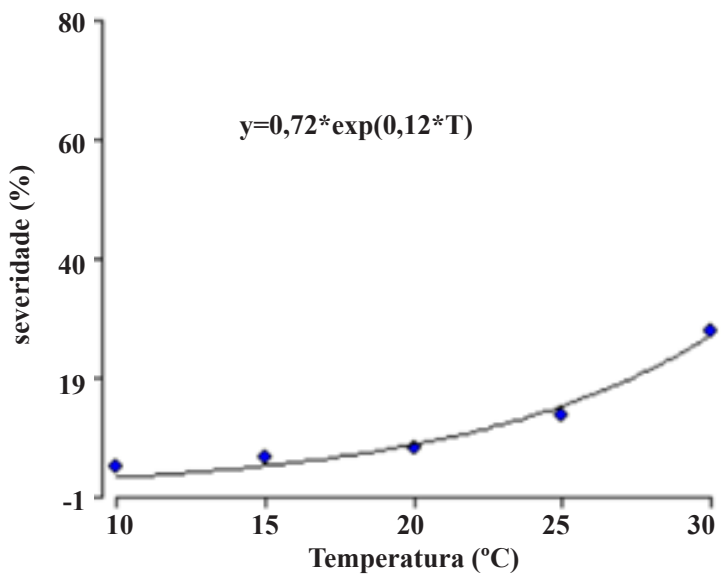

Figura 2. Severidade estimada da mancha-amarela (\%) sob diferentes temperaturas, em duas cultivares de trigo (Mirante e Fundacep Horizonte), após 12 dias da inoculação. UPF, Passo Fundo, 2012.
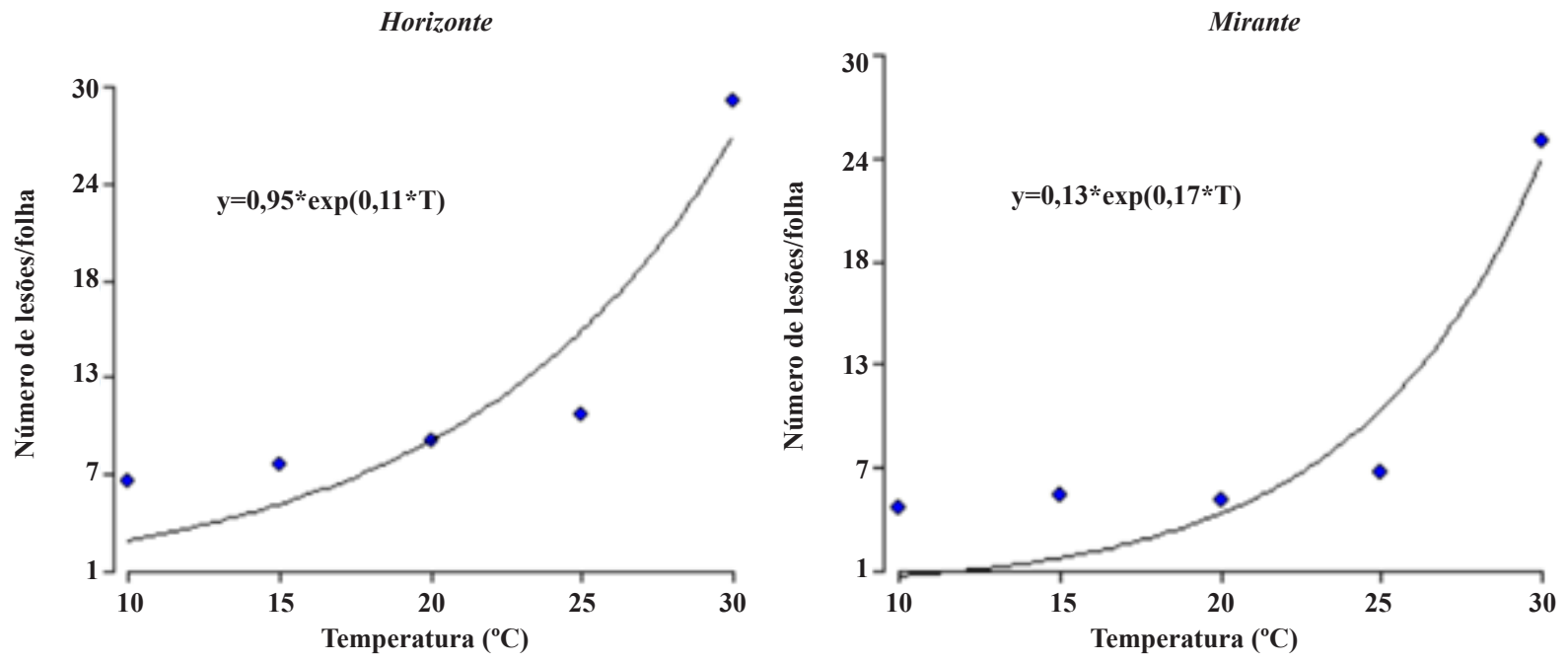

Figura 3. Número de lesões da mancha-amarela sob diferentes temperaturas, em duas cultivares de trigo (Mirante e Fundacep Horizonte) após 12 dias da inoculação. UPF, Passo Fundo, 2014. 
O número de lesões seguiu o mesmo comportamento observado nas duas variáveis analisadas anteriormente. Ocorreram diferenças no número de lesões quando as plantas ficaram expostas a diferentes temperaturas. O maio número de lesões por folha foi de 27,07 na temperatura de $30^{\circ}$ e a de $10^{\circ} \mathrm{C}$ observou-se o mais baixo número de lesões $(5,23)$ (Figura 3). As cultivares também diferiram entre si, onde Fundacep Horizonte apresentou o maior número de lesões. Os resultados estão correlacionados com o que ocorre no campo, onde observa-se que, quando as temperaturas são mais elevadas há uma aceleração no progresso da doença.

\section{AGRADECIMENTO}

A Coordenação de Aperfeiçoamento de Pessoal de Nível Superior (CAPES) e a Universidade de Passo Fundo (UPF), pela bolsa de estudo.

\section{REFERÊNCIAS BIBLIOGRÁFICAS}

1. AMORIM, L.; BEDENDO, I. P. Ambiente e doença. In: REZENDE, J. A.; BERGAMIN FILHO, A.; AMORIM, L.; M. (Ed.) Manual de fitopatologia. 4.ed. Piracicaba: Agronômica Ceres, 2011. 704p 133-146.

2. ECKHARDT, H., STEUBING, L. \& KRANZ, J. Das Koloniewachstum von Erysiphe graminis D. C. f.sp. hordei Marchal in Abhangigkeit von Temperatur and Insertionshole der Blatter. Angewandte Botanik 58:433-443. 1984

3. FERNANDEZ, M. R. Manual para laboratório de fitopatologia. Passo Fundo: EMBRAPA-CNPT, 1995. 126 p.

4. HOSFORD, R. M. Jr.; LAREZ, C. R.; HAMMOND, J. J. Interation of wet period and temperature on Pyrenophora tritici-repentis infection and development in wheats of differing resistance. North Dakota. Phytopathology, v. 77, p. 1021-1027, 1987.

5. LAMARI, L. \& BERNIER, C.C. Evalution of wheat lines and cultivars to tan spot (Pyrenophora tritici-repentis) based on lesion type. Manitoba. Canadian Journal Plant Pathology. 11:49-56, 1989.

6. LAREZ, C.R., HOSFORD Jr., R.M. and FREEMAN, T.P. Infection of wheat and oast by Pyrenophora tritici-repentis and initial characterization of resistance. North Dakota. Phytopathology. 76:931-938, 1986.

7. PRATES, G.L \& FERNANDES, C.J.M. Avaliando a taxa de expansão de lesões de Bipolaris sorokiniana em trigo. Fitopatologia. Brasileira. vol.26 no.2 Brasília Junho 2001. Disponível em: <http://www.scielo.br/ scielo.php?script=sci_arttext\&pid=S0100-41582001000200012>. Acesso em: 22 abril. 2015.

8. REIS, E.M.; BRESOLIN, A.C.R. Sistemas de previsão de doenças de plantas. In: REIS, E.M. Previsão de doenças de plantas. Passo Fundo: UPF, 2004. p.155-287.

9. REIS, E. M; CASA, R.T; DANELLI, A.L.D. Mancha amarela da folha. $2^{\mathrm{a}}$ edição Passo Fundo- RS: Bayer S. A., 2011, 18 p.

10. SAH, D.N. (1994) Effects of leaf wetness duration and inoculum level on resistance of wheat genotypes to Pyrenophora tritici-repentis. Birganj, Nepal. Journal of Phytopathology 142, 324-330.

11. SANTANA, F. M. Atenção às manchas foliares do trigo. Embrapa Trigo, 2009. Disponível em: $<$ http://www.cnpt.embrapa.br/obs_trigo/inf_tecnicas/ manchas_foliares_do_trigo.pdf $>$ Acesso em: 25 abril. 2015 .

12. SHABBER, A., BOCKUS, W.W. Tan spot effects on yield and yield components relative to growth stage in winter wheat. Manhattam. Plant Disease. 72, 599-602, 1988.

13. SUBBARAO, K.V. \& MICHAILIDES, T.J. Effects of temperature on isolates of Fusarium moniliforme causing fig endosepsis and Aspergillus niger causing smut. Phytopathology 85:662-668. 1995. 